\title{
Embryo Preservation
}

National Cancer Institute

\section{Source}

National Cancer Institute. Embryo Preservation. NCI Thesaurus. Code C18760.

Methods for short term or long term preservation of embryos at the two cell stage or beyond. Examples include short term storage in buffered media with serum at reduced temperature and long term cryopreservation in liquid nitrogen. 